\title{
Stochastic Filtering with Applications in Finance
}


This page intentionally left blank 


\section{Stochastic Filtering with Applications in Finance}

\section{Ramaprasad Bhar}

The University of New South Wales, Australia 


\title{
Published by
}

World Scientific Publishing Co. Pte. Ltd.

5 Toh Tuck Link, Singapore 596224

USA office: 27 Warren Street, Suite 401-402, Hackensack, NJ 07601

UK office: 57 Shelton Street, Covent Garden, London WC2H 9HE

\author{
Library of Congress Cataloging-in-Publication Data \\ Bhar, Ramaprasad. \\ Stochastic filtering with applications in finance / by Ramaprasad Bhar. \\ p. cm. \\ Includes bibliographical references and index. \\ ISBN-13: 978-981-4304-85-6 \\ ISBN-10: 981-4304-85-9 \\ 1. Finance--Mathematical models. 2. Stochastic analysis. I. Title. \\ HG106.B434 2010 \\ $332.01^{\prime} 51922--d c 22$
}

2010019089

\section{British Library Cataloguing-in-Publication Data}

A catalogue record for this book is available from the British Library.

Copyright (c) 2010 by World Scientific Publishing Co. Pte. Ltd.

All rights reserved. This book, or parts thereof, may not be reproduced in any form or by any means, electronic or mechanical, including photocopying, recording or any information storage and retrieval system now known or to be invented, without written permission from the Publisher.

For photocopying of material in this volume, please pay a copying fee through the Copyright Clearance Center, Inc., 222 Rosewood Drive, Danvers, MA 01923, USA. In this case permission to photocopy is not required from the publisher.

Printed in Singapore. 
To Rajiv and Mitra

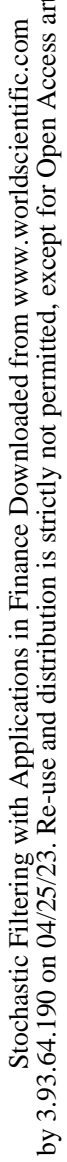


This page intentionally left blank 


\section{Preface}

Stochastic filtering has been in use in engineering and in particular in the area of signal processing for a long time. Its usefulness in financial economics has been recognized for some time. The objective of a filtering application is to determine the best (in some sense) estimate for the states that drive a stochastic dynamical system. The measurable observations that the researchers have are not these states but some linear functions of these states. As an example, we can think of observations on futures prices on some asset, but we do not know anything about the stochastic convenience yield that may be contributing to the futures price formation. Filtering is an iterative process that enables us to estimate the states of the system as well as any hyper-parameters of the models. In the simplest case when there are no gaps in the measurable observations and all observations are made on equal time step, the solution to the problem is the well-known Kalman-Bucy filter. This basic structure, also referred to as state space model, has been found to be a valuable tool within Central Banks as well as financial institutions to deal with difficult inference problems as well for forecasting.

Complications arise when the functions relating to the unobservable states and the measurable observations are not linear. There may be missing observations or the conditional distributions are not necessarily Gaussian or even the time steps between the observations are not equal. To cater to such variations many improvements have been proposed in the literature.

The purpose of this book is to provide a comprehensive account of this very important tool with a view to making it more popular among researchers in finance and economics. It is not intended to give complete 
mathematical treatment of different stochastic filtering approaches, but describe them in simple terms and illustrate their application with real historical data for problems normally encountered in these disciplines. Although no prior knowledge in this area is assumed, the readers are expected to have knowledge of probability theory as well as general mathematical aptitude. The book is intended as a reference for graduate students and researchers interested in the field. It is also suitable for use as a text for a graduate level course on stochastic filtering.

The idea of such a book was growing since I started my own $\mathrm{PhD}$ research. I came to quantitative finance research after working in the information technology area for several years in technical software development and maintenance in commercial organizations. Besides, my early graduate level education in physics encourages a scientific frame of mind to deal with problems in financial economics. I attempted to synthesize the contents based on my life experiences in a diverse range of activities. I sincerely believe that this book will offer fresh perspectives to the readers in dealing with problems encountered in financial economics. The book is less demanding on mathematical aptitude and at the same time conveys the underlying complexities with the help of examples familiar to the readers in the finance and economics disciplines.

The book aims to be an example-driven elucidation of a complex technical area so that it appeals to a wide variety of readers in the discipline of finance and economics. The algorithmic presentation of the models for the applications will help readers to take up new challenges in their own field of study/research. This will also help them to get a clear understanding of the filtering issues quickly and enhance the models that suit their own perceptions.

The first chapter deciphers the notion of filtering and various ways of estimating models under different assumptions. Once this is understood, the succeeding chapters take up relevant applications in finance and economics and show how filtering framework applies in those situations. The second chapter focuses on the foreign exchange market and extracts embedded risk premium in the forward exchange rates. The third chapter explores the notion of risk premium in the equity market with a difference. It analyzes the price of risk and not just the total quantity of risk. 
The fourth chapter revisits an important issue in macroeconomics. This is to do with the notion of inflation uncertainty and its connection with interest rates in the economy. It applies the filtering scheme to extract two forms of uncertainty from the inflation data and then explores its relationship with interest rates with particular reference to countries following inflation targeting policy.

The fifth and sixth chapters move the discussions to the interest rate model proposed by Heath, Jarrow and Morton in 1992. The rich but nonMarkovian dynamics of this approach also entail computational and implementation complexities. These chapters describe how to deal with the issues via expansion of states and stochastic filtering. The examples include bond pricing as well as pricing of interest rate futures contracts.

Chapters 7 through 9 concentrate on fixed income securities. The possible drivers of credit spread are analyzed in Chapter 7 in a filtering framework. Chapter 8 takes up the structure of relatively new security in the credit derivatives market, i.e., credit default swaps. It disentangles the component structure of credit default swaps and analyzes the possible explanatory variables for these components. Chapter 9 moves on to explore the model for pricing options on credit default swaps. A relatively new filtering algorithm is exploited here for model calibration.

Chapter 10 explores different methods for estimation of the stochastic variance model applied to short-term interest rates. It also shows how to enhance the time series dynamics of the unobserved variance process.

Chapter 11 moves away from simply diffusion based filtering problems to those where jumps are also involved. This is illustrated with two examples. The first one is to capture the price path dynamics of spot electricity and the second one examines whether the jump risk could be diversified in the market for credit default swaps index and its subindices.

It is clear from the breadth of coverage in this book that it could not have been accomplished without the help from others. I would like to thank first my PhD students: Peipei Wang, Nedim Handzic and Damien Lee. I wish them all the success in their future endeavors. Also, I am grateful to a colleague of mine, David Colwell, with whom I had many insightful sessions. 
I would also like to express my sincere gratitude to Carl Chiarella, my PhD supervisor at the University of Technology, Sydney. That is when I started learning about the interest rate model due to Heath, Jarrow and Morton and the complexities within the framework.

I am thankful to David Sharp at the World Scientific Press in Singapore for persisting with me to come up with the idea for this book.

Finally, I am grateful to my family for support and patience. My son regularly enquired about the progress of the book while he was studying Engineering at the Imperial College, London.

\section{R. Bhar}

Sydney, 2010 


\section{Contents}

Preface vii

1. Introduction: Stochastic Filtering in Finance

1.1 Filtering Problem 2

1.2 Examples of Filtering Applications 2

1.3 Linear Kalman Filter 3

1.4 Extended Kalman Filter (EKF) 6

1.5 Applying EKF to Interest Rate Model 7

1.6 Unscented Kalman Filter (UKF) for Nonlinear Models 10

1.7 Background to Particle Filter for Non Gaussian Problems 13

$\begin{array}{ll}1.8 \text { Particle Filter Algorithm } & 14\end{array}$

1.9 Unobserved Component Models 16

1.10 Concluding Remarks 19

2. Foreign Exchange Market - Filtering Applications

2.1 Mean Reversion in Real Exchange Rates 21

2.2 Common and Specific Components in Currency Movements 25

2.3 Persistent in Real Interest Rate Differentials 30

2.4 Risk Premia in Forward Exchange Rate 34

2.4.1 Approach based on Market Price of Risk (BCP) 36

2.4.2 Method of Wolff/Cheung $\quad 40$

2.4.3 Data and Empirical Results 41

2.4.4 Summary of Section 2.4

2.5 Concluding Remarks $\quad 47$

3. Equity Market - Filtering Applications

3.1 Introduction to Equity Price of Risk 49

3.1.1 A Model for Equity Price of Risk 51

3.1.2 Data Used for Empirical Study $\quad 52$

3.1.3 Discussion of Empirical Results $\quad 53$

3.1.4 Summary of Results 61 
3.2 Economic Convergence in a Filtering Framework 62

3.2.1 Defining Convergence 64

3.2.2 Testing for Convergence 65

3.2.3 Testing Convergence - Dickey-Fuller 66

3.2.4 Testing Convergence - Kalman Filter 67

3.3 Ex-Ante Equity Risk Premium 69

3.3.1 Background to Ex Ante Risk Premium 69

3.3.2 A Model for Ex Ante Risk Premium 70

3.3.3 Filtering Ex Ante Risk Premium $\quad 72$

3.3.4 Ex-Ante Risk Premium for UK 73

3.3.5 Summarizing Ex-Ante Risk Premium for UK 73

$\begin{array}{ll}3.4 \text { Concluding Remarks } & 75\end{array}$

4. Filtering Application - Inflation and the Macroeconomy

$\begin{array}{ll}\text { 4.1 Background and Macroeconomic Issues } & 77\end{array}$

$\begin{array}{ll}\text { 4.2 Inflation Targeting Countries and Data Requirement } & 79\end{array}$

4.3 Model for Inflation Uncertainties $\quad 80$

4.4 Testing Fisher Hypothesis $\quad 82$

4.5 Empirical Results and Analysis $\quad 83$

4.6 Concluding Remarks $\quad 85$

5. Interest Rate Model and Non-Linear Filtering

5.1 Background to HJM Model and the Related Literature 95

5.2 The Basic HJM Structure 97

5.3 Forward Rate Volatility: Deterministic Function of Time 100

5.4 Forward Rate Volatility: Stochastic 102

$\begin{array}{ll}\text { 5.5 Estimation via Kalman Filtering } & 107\end{array}$

5.6 Preference-Free Approach to Bond Pricing 109

5.7 Concluding Remarks $\quad 112$

Appendix 5.1 Arbitrage-Free SDE for the Bond Price 114

Appendix 5.2: Proof of Proposition $1 \quad 117$

Appendix 5.3: Proof of Proposition $2 \quad 119$

Appendix 5.4: Proof Proposition $3 \quad 122$

6. Filtering and Hedging using Interest Rate Futures

6.1 Background Details 126

6.2 The Futures Price Model in the HJM Framework 127

6.3 Non-Linear Filter for Futures Price System 131

6.4 Data Used in Empirical Study 134

6.5 Empirical Results $\quad 135$

6.6 Concluding Remarks 138

Appendix 6.1 139 
7. A Multifactor Model of Credit Spreads

7.1 Background and Related Research

7.2 Variables Influencing Changes in Credit Spreads 151

7.3 Credit Spread and Default Risk 153

7.4 Credit Spread and Liquidity 155

7.5 Alternative Approach to Analyzing Credit Spread 156

$\begin{array}{ll}7.6 \text { Data Used } & 159\end{array}$

7.7 Multifactor Model for Credit Spread 160

7.8 Fitting the Model $\quad 162$

7.9 Results 162

7.9.1 Results for Apr-96 to Mar-03 162

7.9.2 Results for Apr-96 to Mar-08 165

$\begin{array}{ll}\text { 7.9.3 Model Performance } & 168\end{array}$

$\begin{array}{ll}\text { 7.9.4 Discussion } & 168\end{array}$

$\begin{array}{ll}7.10 \text { Concluding Remarks } & 169\end{array}$

8. Credit Default Swaps - Filtering the Components

8.1 Background to Credit Default Swaps 185

8.2 What is in the Literature Already? 188

8.3 Credit Derivatives Market and iTraxx Indices $\quad 190$

8.4 CDS Index Data and Preliminary Analysis $\quad 192$

8.5 Focusing on Explanatory Variables 195

8.6 Methodology for Component Structure 201

8.6.1 Latent-Component Model for iTraxx Indices 201

8.6.2 State Space Model and Stochastic Filtering 203

8.6.3 Linear Regression Model for the Determinants of the CDS

Components 204

8.7 Analyzing Empirical Results 205

8.7.1 Model Parameters and the Extracted Components 205

8.7.2 Determinants of the Extracted Components 207

8.8 Concluding Summary 211

9. CDS Options, Implied Volatility and Unscented Kalman Filter

9.1 Background to Stochastic Volatility 230

9.2 Heston Model in Brief 231

9.3 State Space Framework $\quad 232$

9.3.1 Transition Equation $\quad 232$

9.3.2 Measurement Equation: CDS Option Price 233

9.3.3 Measurement Equation Derivation $\quad 235$

9.4 General State Space Model and Filter Revisited 237

9.4.1 Additive Non-Linear State Space model (Recap) 238

9.4.2 The Scaled Unscented Transformation (Recap) 240 
9.5 The Application of Unscented Kalman Filter

9.6 Empirical Results

9.7 Concluding Remarks

10. Stochastic Volatility Model and Non-Linear Filtering Application

10.1 Background to Stochastic Volatility Models

10.2 Stochastic Volatility Models of Short-term Interest Rates

10.2.1 SV-ARMA Specification

10.2.2 Exogenous Variables

10.3 Data for Analysis

10.4 Analysis of Estimation Results

10.5 Comparison of Volatility Estimates

10.6 Outline of State Space Model Estimation via MCL

10.7 Concluding Summary

11. Applications for Filtering with Jumps

11.1 Background to Electricity Market and Prices

11.2 A Model for Spot Electricity Prices 288

11.3 State Space Model, Kalman Filter and Poisson Jumps 291

11.4 Data and Empirical Results for Electricity Market 294

11.5 Summarizing Electricity Market Application 296

11.6 Background to Jumps in CDS Indices 297

$\begin{array}{ll}\text { 11.7 CDS Data and Preliminary Analysis } & 300\end{array}$

11.8 Methodology for Analyzing CDS Jump Risks 301

11.8.1 Normality Test for CDS Index Distribution 301

11.8.2 Model for Individual iTraxx Indices 301

11.8.3 Multivariate Analysis of Jumps in iTraxx Index with One Latent Common Factor

11.9 Analysis of Results from the CDS Market $\quad 307$

11.10 Summarizing CDS Market Application 308

$\begin{array}{ll}\text { Bibliography } & 320\end{array}$

$\begin{array}{ll}\text { Index } & 337\end{array}$ 